\title{
Age-Hardenability and Related Microstructural Changes During and After Phase Transformation in an Au-Ag-Cu-based Dental Alloy
}

\author{
Hyung-Il Kim, Tae-Wan Kim, Young-Oh Kim, Su-Yeon Cho,
} Gwang-Young Lee, Yong Hoon Kwon, Hyo-Joung Seol**

\author{
Department of Dental Materials, School of Dentistry and Medical Research Institute, \\ Pusan National University, Beomeo-Ri, Mulgeum-Eup, Yangsan-Si, \\ Gyeongsangnam-Do, 626-814, South Korea
}

Received: May 25, 2012; Revised: July 23, 2012

\begin{abstract}
The aim of this study was to clarify how the microstructural changes during and after phase transformation determine the age-hardenability of an $\mathrm{Au}-\mathrm{Ag}$-Cu-based dental alloy. The rapid increase in hardness in the initial stage was the result of rapid atomic diffusion by spinodal decomposition into metastable Ag-rich' and Cu-rich' phases. The constant hardening after apparent initial hardening was the result of a subsequent transformation of the metastable Ag-rich' and $\mathrm{Cu}$-rich' phases to the stable Ag-rich $\alpha_{1}$ phase and $\mathrm{AuCu}$ I phase through the metastable $\mathrm{AuCu}$ I' phase. During the increase in hardness, fine block-like structure with high coherency formed in the grain interior, which changed to a fine cross-hatched structure. A relatively coarse lamellar structure composed of Ag-rich $\alpha_{1}$ and $\mathrm{AuCu} I$ phases grew from the grain boundaries, initiating softening before the grain interior reached its maximum hardness. As a result, the spinodal decomposition attributed to rapid hardening by forming the fine block-like structure, and the subsequent ordering into $\mathrm{AuCu}$, which is a famous hardening mechanism, weakened its hardening effect by accelerating the lamellar-forming grain boundary reaction.
\end{abstract}

Keywords: spinodal decomposition, metastable phase, age-hardening, lamellar-forming grain boundary reaction

\section{Introduction}

Silver-added $\mathrm{Au}-\mathrm{Cu}$ alloys for dental fabrication are designed to be age-hardenable so as to be used for single units to long span bridges and implant retained superstructures that are subject to very high forces ${ }^{1,2}$. In many aspects, it is desirable for dental casting Au-Ag-Cu-based alloys to be age-hardened sufficiently within a short period of time. The effective range of aging temperature which can afford is restrictive, and thus the available age-hardening mechanism of the alloys also becomes restrictive. Regarding $\mathrm{Au}-\mathrm{Ag}-\mathrm{Cu}$-based alloys, age-hardenability is related to phase separation into $\mathrm{Ag}$-rich and $\mathrm{Cu}$-rich phases, and the separated phases may or may not transform to an ordered phase with or without tetragonality, possibly through a metastable state ${ }^{3-7}$. In a previous study with a dental $\mathrm{Au}-\mathrm{Ag}-\mathrm{Cu}$ alloy with relatively high zinc content aged at $400{ }^{\circ} \mathrm{C}$, the alloy was decomposed spinodally into $\mathrm{Ag}$-rich and $\mathrm{Cu}$-rich phases through a metastable state without subsequent ordering of the $\mathrm{Cu}$-rich phase into the $\mathrm{AuCu}$ I phase. The hardness increased from 200 (HV) to 250 (HV) within very short time periods (e.g. 12 seconds) owing to spinodal decomposition, and then increased constantly to 280 (HV) up to 5000 minutes $^{4}$. Considering

*e-mail: seol222@pusan.ac.kr the above study, it can be thought that if the alloy went through the subsequent ordering into the $\mathrm{AuCu}$ I phase after spinodal decomposition, the alloy would have more apparent age-hardenenability. However, Udoh et al. ${ }^{5}$, who examined a $40 \mathrm{Au}-30 \mathrm{Ag}-30 \mathrm{Cu}$ (at.\%) experimental alloy reported almost equal age-hardenenability regardless of the subsequent ordering of the $\mathrm{Cu}$-rich phase to the $\mathrm{AuCu}$-type phase after spinodal decomposition by aging at $250-375^{\circ} \mathrm{C}^{5}$. Such a result is related to the fact that the age-hardenability of dental Au-Ag-Cu-based alloys is affected by the start point of the softening mechanism because the age-hardenability of an alloy will be declined when the softening mechanism is initiated before the alloy reaches the maximum hardness. Despite several studies on age-hardening of Au-Ag-Cu-based alloys $^{5-8}$, the microstructural changes related to softening during and after phase transformation and their relationship with age-hardenability has not been fully clarified yet. In the present study, the isothermal age-hardening behavior and related phase transformation, microstructural changes and elemental distribution of an $\mathrm{Au}-\mathrm{Ag}$-Cu-based dental alloy were examined to clarify how the microstructural changes during and after phase transformation determine the age-hardenability of an Au-Ag-Cu-based dental alloy. 


\section{Material and Methods}

\subsection{Specimen alloy}

The alloy used in the present study was a yellow $\mathrm{Au}-\mathrm{Ag}-\mathrm{Cu}$ alloy (Aurium56, Aurium research, U.S.A.), which belongs to Type 2-4 that is usable for single units to long span bridges and implant retained superstructures by the ISO classification (ISO 22674:2006(E)). Table 1 lists the chemical composition of the alloy. The initial shape of the specimen was plate-like with dimensions of $8 \mathrm{~mm} \times 8.5 \mathrm{~mm} \times 1 \mathrm{~mm}$, and was procured in a rolled and annealed state.

\subsection{Hardness test}

Before hardness testing, the specimens were solution-treated at $700{ }^{\circ} \mathrm{C}$ for 15 minutes under an argon atmosphere, and then rapidly quenched into ice brine to preclude microstructural changes on cooling. They were subsequently aged isochronally for 10 and 20 minutes in the temperature range $250{ }^{\circ} \mathrm{C}$ to $500{ }^{\circ} \mathrm{C}$, and were isothermally aged at $400{ }^{\circ} \mathrm{C}$. All aging was done in a molten salt bath $\left(25 \% \mathrm{KNO}_{3}+30 \% \mathrm{KNO}_{2}+25 \% \mathrm{NaNO}_{3}+20 \%\right.$ $\mathrm{NaNO}_{2}$ ), followed by quenching into ice brine. Hardness measurements were made using a Vickers micro-hardness tester (MVK-H1, Akashi Co., Japan) with a load of $300 \mathrm{~g}-\mathrm{f}$ and a dwell time of 10 seconds. Vickers hardness results were recorded as the average values of five measurements.

\subsection{X-ray diffraction study}

For the X-ray diffraction (XRD) study, powder specimens which passed through a 300-mesh screen were obtained by filing the plate-like samples. After being vacuum-sealed in a silica tube and solution-treated at $700{ }^{\circ} \mathrm{C}$ for 15 minutes, they were isothermally aged at $400{ }^{\circ} \mathrm{C}$ for various periods of time in a molten salt bath, and then quenched into ice brine. The X-ray diffraction profiles were recorded by an X-ray diffractometer (XPERT-PRO, Philips, Netherlands). The X-ray diffractometer was operated at $30 \mathrm{kV}$ and $40 \mathrm{~mA}$, using Nickel-filtered $\mathrm{Cu} \mathrm{K} \alpha$ radiation. The scanning rate of a goniometer was $2^{\circ}(2 \theta / \mathrm{min})$.

\subsection{Field emission scanning electron microscopic observations}

For the field emission scanning electron microscopic (FE-SEM)observations, the plate-like samples were subjected to the required heat treatment, and then prepared by utilizing standard metallographic techniques. A freshly prepared aqueous solution of $10 \%$ potassium cyanide $(\mathrm{KCN})$ and $10 \%$ ammonium persulfate $\left(\left(\mathrm{NH}_{4}\right)_{2} \mathrm{~S}_{2} \mathrm{O}_{8}\right)$ was used for the final etching of the samples. The specimens were examined at $15 \mathrm{kV}$ using a field emission scanning electron microscope (JSM-6700F, JEOL, Japan).

Table 1. Chemical composition of the alloy.

\begin{tabular}{cccccccc}
\hline Composition & Au & Ag & Cu & Pd & Zn & In & Ir \\
\hline wt. (\%) & 55.8 & 25.0 & 13.8 & 4.1 & 1.0 & $<1$ & $<1$ \\
at. (\%) & 35.9 & 29.4 & 27.5 & 4.9 & 1.9 & $<1$ & $<1$ \\
\hline
\end{tabular}

\subsection{Energy dispersive spectrometer analysis}

Energy dispersive spectrometer (EDS) analysis was done to observe the chemical distribution of the elements in the alloy during the aging process. The specimens were prepared in the same manner as was used for the scanning electron microscopic observations. The specimens were examined at $15 \mathrm{kV}$ and $7 \mathrm{kV}$ using a field emission scanning electron microscope (JSM-6700F, JEOL, Japan) equipped with an energy dispersive X-Ray spectrometer (INCA $\mathrm{x}$-sight, Oxford Instruments Ltd., UK).

\section{Results and Discussion}

\subsection{Age-hardening behavior}

Figure 1 shows the isochronal age-hardening curves of the alloy solution-treated at $700{ }^{\circ} \mathrm{C}$ for 15 minutes, and then aged at temperatures ranging from $250{ }^{\circ} \mathrm{C}$ to $500{ }^{\circ} \mathrm{C}$ for 10 and 20 minutes. The alloy exhibited maximum age-hardenability at $400{ }^{\circ} \mathrm{C}$, which was $50{ }^{\circ} \mathrm{C}$ higher than that suggested by the manufacturer. Relatively little difference was seen between the specimens aged for 10 and 20 minutes. Figure 2 shows the isothermal age-hardening curve of the alloy solution-treated at $700{ }^{\circ} \mathrm{C}$ for 15 minutes and then aged at $400{ }^{\circ} \mathrm{C}$ for various times. The hardness increased apparently from 187 to 245 (HV) within 12 seconds without an incubation period. The hardness then increased constantly to 290 (HV) after aging for 100 minutes. The maximum value was maintained until 200 minutes, and then decreased constantly to 204 (HV) by prolonged aging until 20,000 minutes.

From the above, the hardness increased apparently from the initial stage of aging. Such a rapid increase in hardness in $\mathrm{Au}-\mathrm{Ag}-\mathrm{Cu}$ alloys is possible by the help of quenched-in excess vacancies when the phase separation occurs by a nucleation and growth mechanism, or possible when the phase separation occurs by spinodal decomposition ${ }^{6,7,9-11}$.

\subsection{Phase transformation}

To understand the mechanism of rapid hardening and subsequent softening, the phase transformation

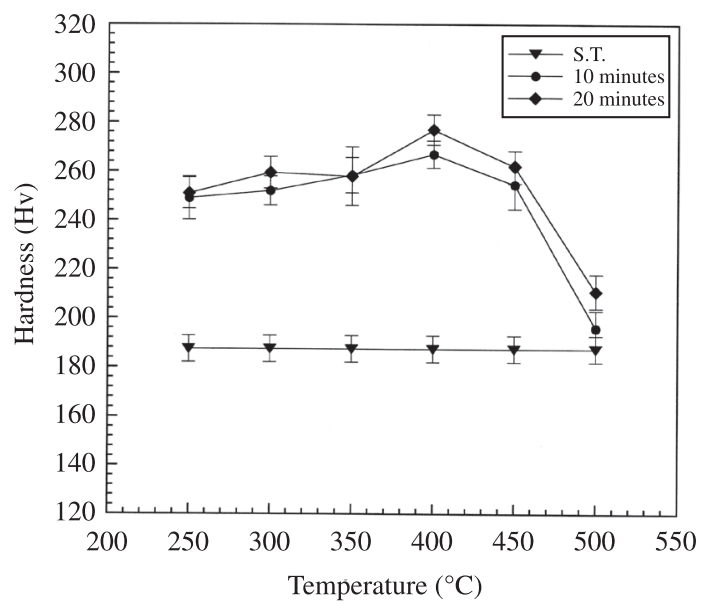

Figure 1. Isochronal age-hardening curves of the alloy aged in the temperature range of $250{ }^{\circ} \mathrm{C}$ to $500{ }^{\circ} \mathrm{C}$ for 10 and 20 minutes. 


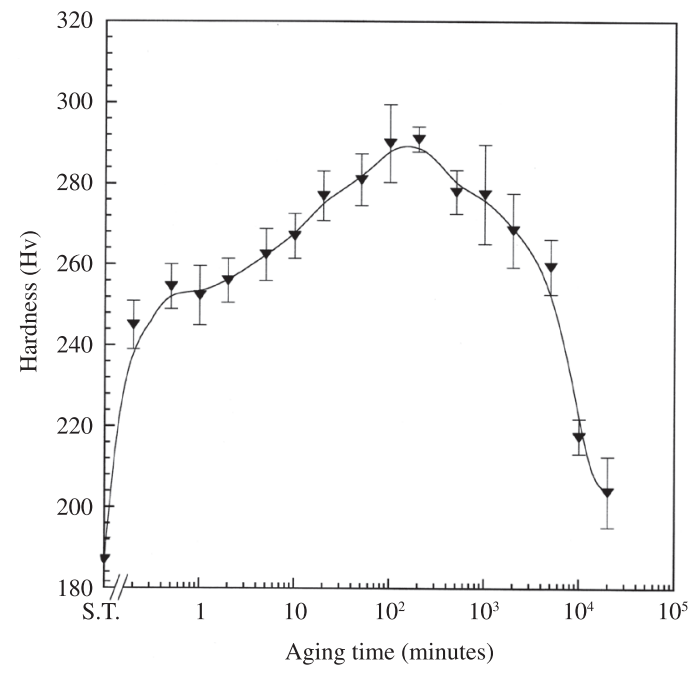

Figure 2. Isothermal age-hardening curve of the alloy aged at $400{ }^{\circ} \mathrm{C}$. with aging was observed by X-ray diffraction (XRD) study. Figure 3 shows the changes in the XRD pattern during $400{ }^{\circ} \mathrm{C}$ isothermal aging. In the solution-treated specimen, a face-centered cubic (f.c.c.) single phase was obtained. The f.c.c. phase $\left(\alpha_{0}\right)$ had a lattice parameter of $a_{200}=0.3948 \mathrm{~nm}$. By aging the solution-treated specimen for 20,000 minutes, the parent f.c.c. $\alpha_{0}$ phase had separated into an f.c.c. Ag-rich $\alpha_{1}$ phase with a slight increase in lattice parameter, $a_{200}=0.4063 \mathrm{~nm}$, and a face-centered tetragonal (f.c.t.) $\mathrm{AuCu}$ I phase with $a_{200}=0.3919 \mathrm{~nm}$ and axial ratio $(c / a)=9.42$.

The changes in the XRD patterns at $400{ }^{\circ} \mathrm{C}$ were examined with respect to the isothermal age-hardening curve at $400{ }^{\circ} \mathrm{C}$ (Figure 2). Both sides of the parent (111) $\alpha_{0}$ peak became broad after aging the solution-treated specimen for 30 seconds. At an aging time of 5 minutes, the side bands which were marked by oblique lines along the (111) $\alpha_{0}$ peak showed strong intensity, and beside the side bands, there were metastable (m) and stable (s) (111)

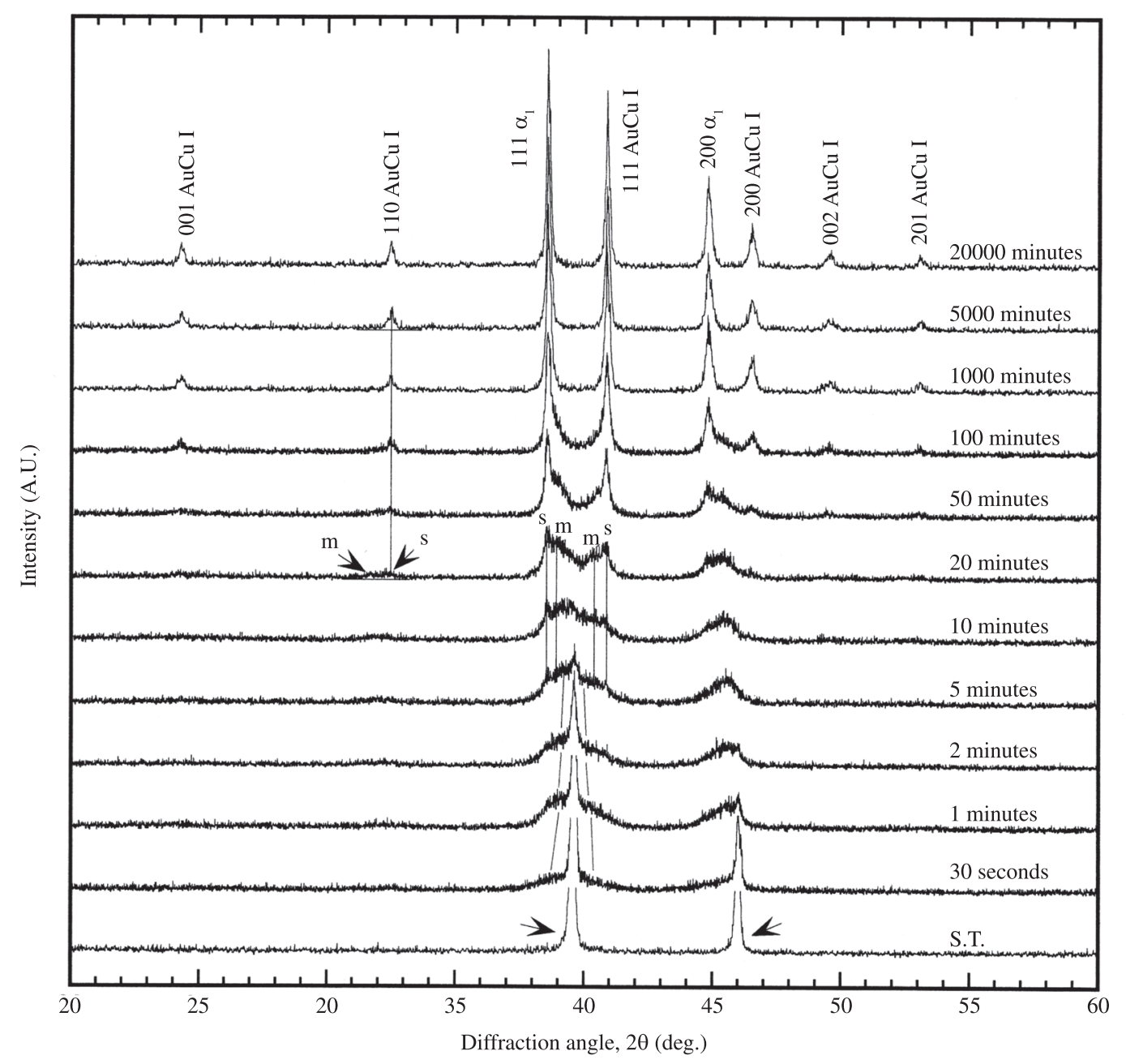

Figure 3. Variations of the XRD patterns as a function of isothermal aging time at $400{ }^{\circ} \mathrm{C}$. 
peaks of $\alpha_{1}$ and $\mathrm{AuCu}$ I phases, which were marked by straight lines in both sides of the parent (111) $\alpha_{0}$ peak. At an aging time of 20 minutes when the hardness was increased constantly, the parent (111) $\alpha_{0}$ peak had almost disappeared, and the peak intensity of the stable $\alpha_{1}$ and $\mathrm{AuCu}$ I phases was stronger than that of the metastable $\alpha_{1}$, and $\mathrm{AuCu}$ I' phases (here, prime (') indicates a metastable state). The (110) peaks of the metastable and stable AuCu I phases were observed near $32^{\circ}(2 \theta)$, and from the difference in peak position, the metastable phase had a larger lattice parameter, $a$, than the stable phase, which minimized the gap in the lattice parameter with the parent $\alpha_{0}$ phase. At an aging time of 100 minutes when the maximum hardness value had been obtained, the (110) peak of the metastable $\mathrm{AuCu}$ I' phase disappeared, and the (200) and (002) peaks of the stable $\mathrm{AuCu}$ I phase became apparent. Therefore, the lattice distortion by the tetragonality must have increased in the inter-phase boundaries of the product phases. After that time, there were no further changes in the diffraction patterns except for the slight peak sharpening by prolonged aging until 20,000 minutes.

From the above, the rapid increase in hardness in the initial stage of the aging process resulted from rapid atomic diffusion by spinodal decomposition considering the side bands that appeared in both sides of the main $111 \alpha_{0}$ peak, as will be further mentioned in the FE-SEM observation $^{6,9,11,12}$. During the apparent initial hardening, the single-phased matrix decomposed spinodally into the metastable Ag-rich' and Cu-rich' phases. Subsequently, the metastable Ag-rich $\alpha_{1}{ }^{\prime}$ phase transformed to a stable $\alpha_{1}$ phase with an increased lattice parameter, and the metastable $\mathrm{Cu}$-rich' phase transformed into the stable $\mathrm{AuCu} \mathrm{I}$ phase with tetragonality through the metastable $\mathrm{AuCu}$ I' phase. This corresponds to the constant hardening that occurred after apparent initial hardening. The metastable Ag-rich $\alpha_{1}$ ' and $\mathrm{AuCu}$ I' phases had a relatively similar lattice parameter to that of the parent $\alpha_{0}$ phase compared to the stable Ag-rich $\alpha_{1}$ and $\mathrm{AuCu}$ I phases. Therefore, the matrix during the early phase transformation must have contained coherent or semi-coherent strain fields ${ }^{8}$. Their transformation into the stable phases with tetragonality increased the gap in the lattice parameters between the product phases, resulting in a possible loss of coherency. However, considering the constant hardening during that time, the fine inter-phase boundaries between the product phases must have contained large amounts of internal strain by lattice distortion. During the period where the hardness decreased, there were no further changes in the diffraction pattern except for peak sharpening, which indicates the release of lattice strain without further phase transformation ${ }^{13,14}$. Therefore, microstructural changes related to the release of lattice strains were supposed in the later stage of the aging process.

\subsection{Microstructural changes}

Field emission scanning electron microscopic (FE-SEM) observations were performed to clarify the microstructural changes occurring during the hardness changes. Figure 4 shows FE-SEM micrographs of $\times 1000$ (1), $\times 6000$ (2) and $\times 50,000$ (3) for the specimen solution-treated at $700{ }^{\circ} \mathrm{C}$ for 15 minutes (a) and aged at $400{ }^{\circ} \mathrm{C}$ for the following time periods: 20 minutes (b), 100 minutes (c), 1000 minutes (d), 5000 minutes (e) and 20,000 minutes (f). The solution-treated specimen was slightly over-etched to clearly observe the changes in the grain interior. In Figure 4(a1), a single phase of an equiaxed structure was obtained. In the magnified Figure 4(a3), the grain interior had a particle- or dendrite-like structure. At an aging time of 20 minutes, the lamellar-forming grain boundary reaction was initiated. The change in the grain interior was unclear in Figure 4(b1), but in the magnified Figure 4(b3), a fine block-like structure appeared between the particle- or dendrite-like structure. At an aging time of 100 minutes when the maximum hardness was obtained, the grain boundary lamellar structure grew further into the grain interior without coarsening the inter-lamellar space (c). In the magnified Figure 4(c3), the particle- or dendrite-like structure was mostly replaced by the much coarsened block-like structure than that observed at 20 minutes. In the corresponding XRD pattern at 100 minutes, the phase transformation was almost completed. Hence, the block-like structure with high coherency must have been arranged by alternating Ag-rich $\alpha_{1}$ and $\mathrm{AuCu}$ I with tetragonality ${ }^{5}$. Their inter-phase boundaries must have contained large amounts of internal strain due to the gap in the lattice parameter, resulting in constant hardening. The previous study with a dental Au-Ag-Cu alloy with relatively high $\mathrm{Zn}$ content reported a similar fine block-like structure ${ }^{4}$. Considering that the present alloy went through the same phase transformation process with the previous alloy except for further ordering of the $\mathrm{Cu}$-rich phase to $\mathrm{AuCu} \mathrm{I}$, the common block-like structure appeared to be formed as a result of spinodal decomposition regardless of the tetragonality by the ordered $\mathrm{AuCu}$ I phase. In the present study, the alloy showed a vigorous lamellar-forming grain boundary reaction unlike the previous alloy. Considering the XRD pattern at an aging time of 5 minutes (Figure 3), which revealed the final Ag-rich $\alpha_{1}$ and $\mathrm{AuCu}$ I phases in the initial stage of the phase transformation together with their metastable phases, it is believed that the grain boundary, which is a relatively easy region for atomic diffusion, underwent a faster phase transformation compared to the grain interior, or underwent a phase transformation without a metastable state into the ordered $\mathrm{AuCu} \mathrm{I}$ phase ${ }^{7,8}$. Therefore, the tetragonality must have increased previously in the grain boundary rather than the grain interior, and which derived the lamellar-forming grain boundary reaction, the powerful softening mechanism ${ }^{7,9}$.

At an aging time of 1000 minutes when the hardness decreased slightly, the grain boundary lamellar structure grew further into the grain interior, and the inter-lamellar space increased significantly $(\mathrm{d} 3)$. The block-like grain interior structure changed to a fine cross hatched structure. Such a structural change in the grain interior was similar to the previous study with a dental $\mathrm{Au}-\mathrm{Ag}-\mathrm{Cu}$ alloy with relatively high $\mathrm{Zn}$ content ${ }^{4}$. In that report, the microstructural changes in the block-like structure into a cross-hatched structure did not cause apparent softening. Considering such a fact, it was thought that the decrease in hardness of the present alloy until 1000 minutes was mainly the result of a lamellar-forming grain boundary reaction. At an aging time 


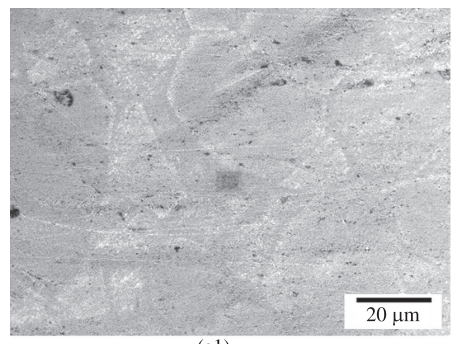

(a1)

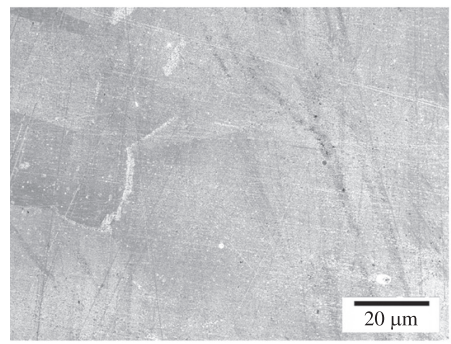

(b1)

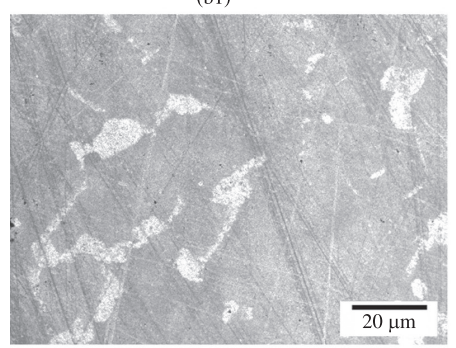

(c1)

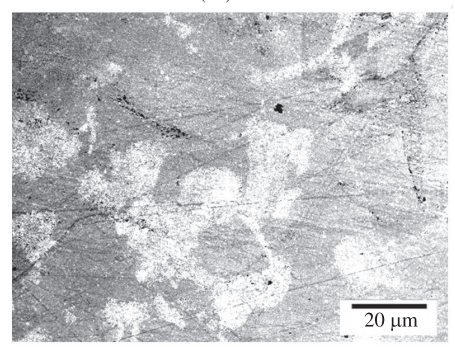

(d1)

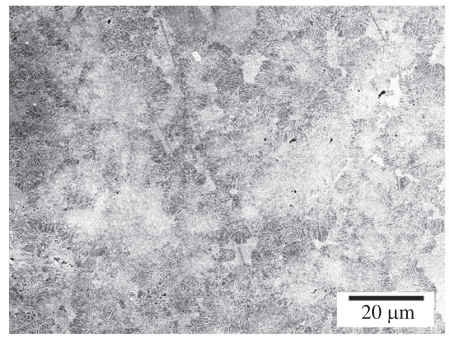

(e1)

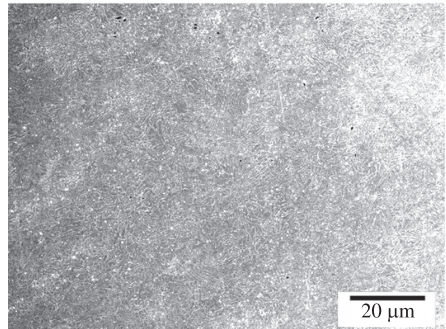

(f1)

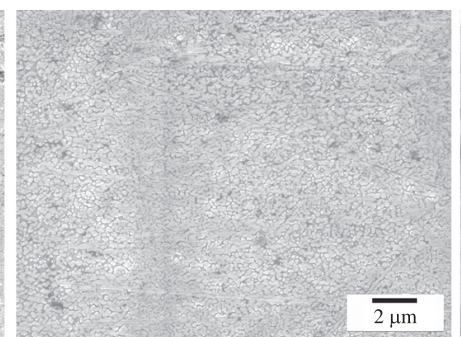

(a2)

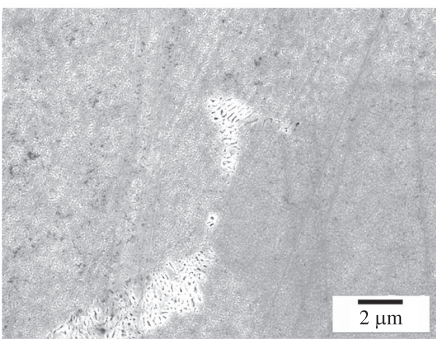

(b2)

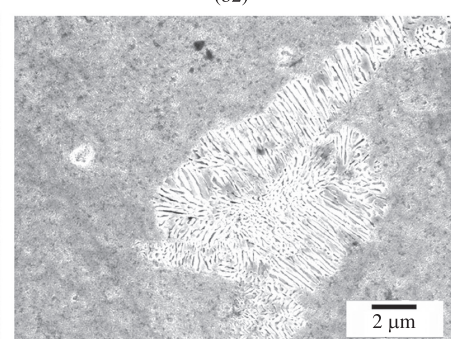

(c2)

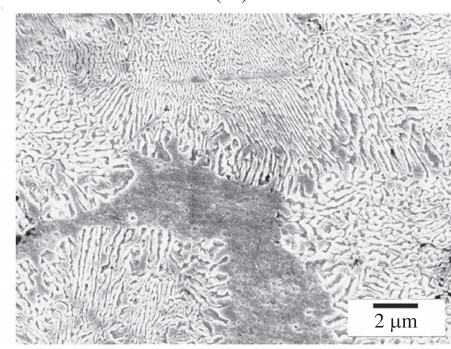

(d2)

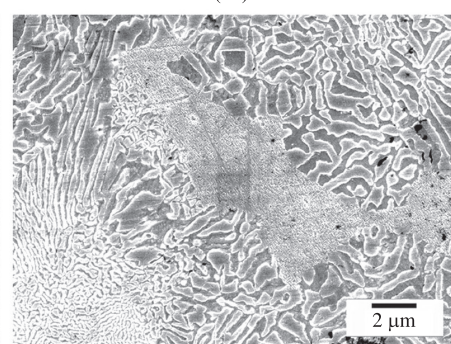

(e2)

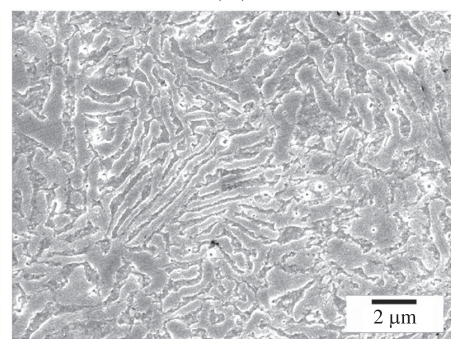

(f2)

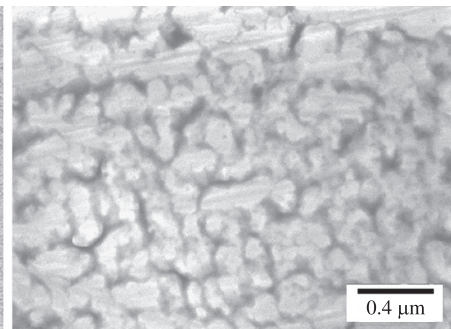

(a3)

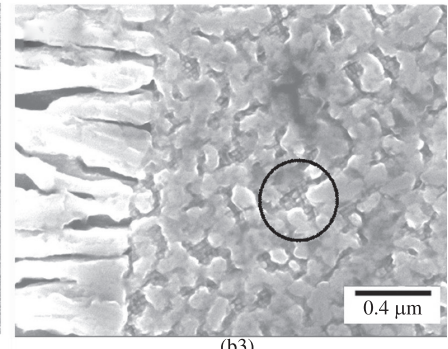

(b3)

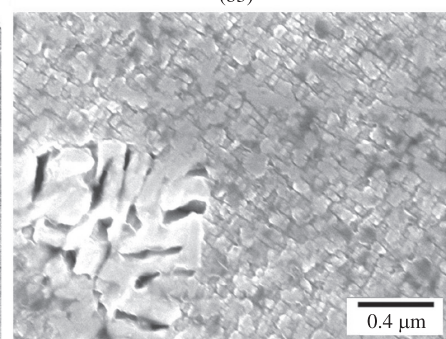

(c3)

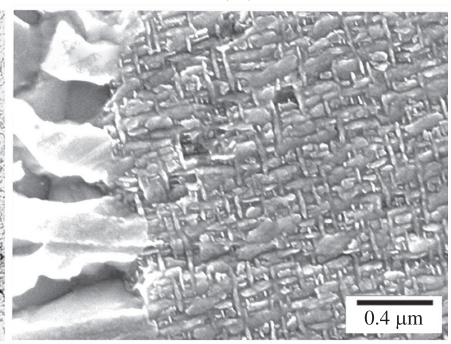

(d3)
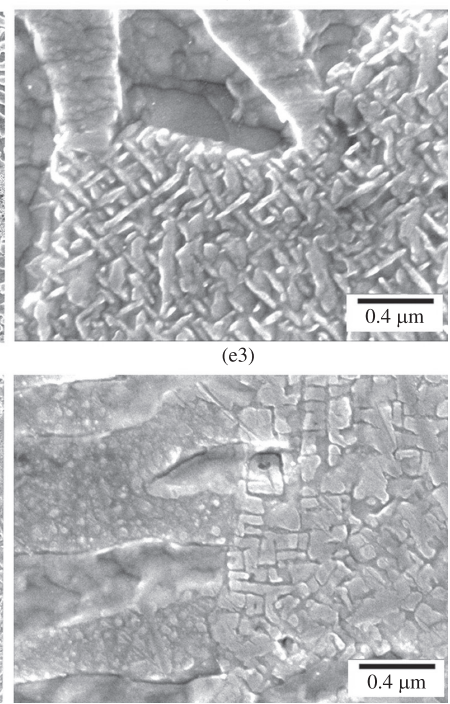

(f3)

Figure 4. FE-SEM micrographs of specimens (a) solution-treated at $700{ }^{\circ} \mathrm{C}$ for 15 minutes and aged at $400{ }^{\circ} \mathrm{C}$ for (b) 20 minutes, (c) 100 minutes, (d) 1000 minutes, (e) 5000 minutes and (f) 20,000 minutes. (1): $\times 1000$; (2): $\times 6000 ;$; 3 ): $\times 50,000$. 


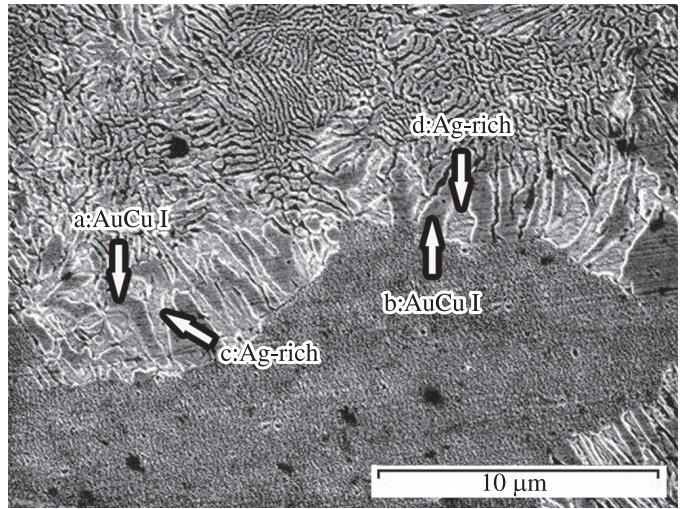

Figure 5. FE-SEM micrograph of specimen aged at $400{ }^{\circ} \mathrm{C}$ for 5000 minutes. of 5000 minutes (e3), both the lamellar structure in the grain boundary and the cross hatched structure in the grain interior coarsened significantly, which resulted in a further decrease in hardness. In the alloy over-aged for 20,000 minutes, the coarse lamellar structure covered almost the entire matrix, and the remaining extremely limited region in the grain interior coarsened to a block-like structure again.

From the above, the grain boundary lamellar structure encroached on the relatively fine grain interior, initiating softening before the grain interior reached its maximum hardness. The lamellar-forming grain boundary reaction and coarsening of the microstructure reduced the inter-phase boundaries among the existing phases which have different lattice parameters. This released the accumulated internal strain, resulting in softening ${ }^{7,9,15}$, as indicated from the sharpening of the broad XRD peaks during the decrease in hardness (Figure 3).
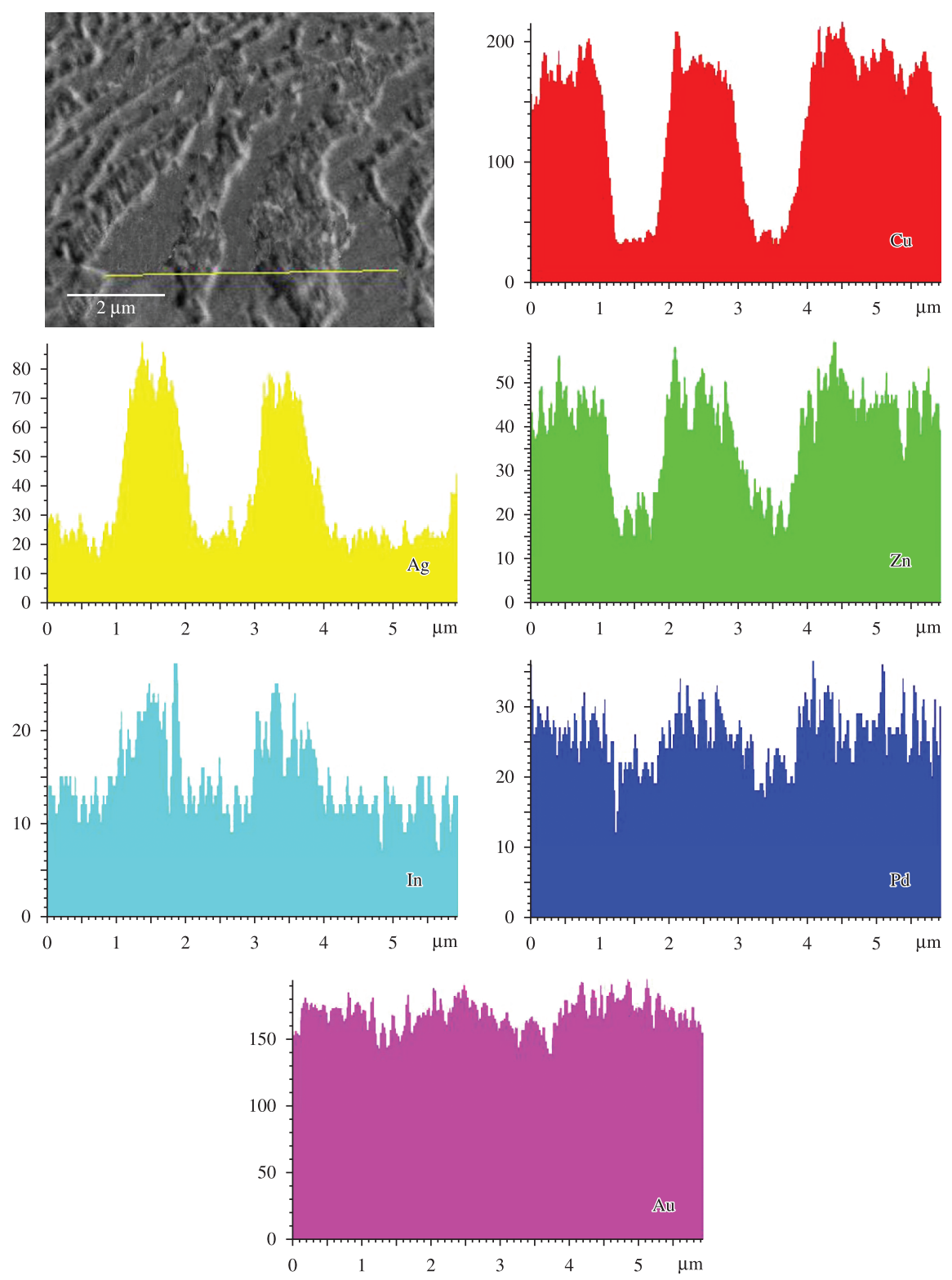

Figure 6. FE-SEM micrograph of specimen aged at $400{ }^{\circ} \mathrm{C}$ for 20,000 minutes, and the results of line analysis for each component. 
Table 2. EDS analysis at the regions marked in Figure 5.

\begin{tabular}{cccccccc}
\hline Region (at. (\%)) & Au & Ag & Cu & Pd & Zn & In & Ir \\
\hline a & 34.4 & 1.9 & 52.5 & 7.6 & 3.6 & - & - \\
b & 36.3 & 0 & 51.9 & 7.4 & 4.4 & - & - \\
c & 38.8 & 54.9 & 6.3 & - & - & - & - \\
d & 39.1 & 54.8 & 6.1 & - & - & - & - \\
\hline
\end{tabular}

\subsection{Changes in elemental distribution}

The elemental distribution in the alternating layers of the lamellar structure was examined by energy dispersive spectrometric (EDS) analysis at an accelerating voltage of $15 \mathrm{kV}$, and the results were shown in Table 2. Figure 5 shows a FE-SEM micrograph of the specimen aged at $400{ }^{\circ} \mathrm{C}$ for 5000 minutes. The (a, b) layers of the lamellar structure were a $\mathrm{Cu}$-rich phase containing large amounts of $\mathrm{Au}$ and small amounts of $\mathrm{Pd}$ and $\mathrm{Zn}$. The neighbouring (c, d) layers of the lamellar structure were the Ag-rich phase containing large amounts of $\mathrm{Au}$ and small amounts of $\mathrm{Cu}$. Therefore, it was clear that the miscibility limit of $\mathrm{Ag}$ and $\mathrm{Cu}$ resulted in an alternating Ag-rich and Cu-rich lamellar structure ${ }^{16}$. Nano scale line analysis of the alloy was performed by EDS analysis by reducing the accelerating voltage to $7 \mathrm{kV}$. Figure 6 shows FE-SEM micrograph of the specimen aged at $400{ }^{\circ} \mathrm{C}$ for 20,000 minutes and the results of line analysis for each component. The distribution of $\mathrm{Cu}$ was opposite to that of Ag. The distribution of minor components, $\mathrm{Pd}$ and $\mathrm{Zn}$, coincided with that of $\mathrm{Cu}$, and the distribution of $\mathrm{In}$ coincided with that of $\mathrm{Ag}$. Au, which is completely soluble in all atomic ratios with both $\mathrm{Ag}$ and $\mathrm{Cu}$, showed a relatively equal distribution in each layer of lamellar structure ${ }^{16}$.

From the above, the present alloy which was hardened by the combination of spinodal decomposition and ordering through a metastable state did not show relatively powerful age-hardenability compared to the only spinodally decomposed $\mathrm{Au}-\mathrm{Ag}-\mathrm{Cu}$ alloy with relatively high $\mathrm{Zn}$ content due to initiation of the lamellar-forming grain boundary reaction before the grain interior reached its maximum hardness ${ }^{4}$. Thus, it can be said that the spinodal decomposition attributed to the rapid initial hardening of

\section{References}

1. Rivolta B and Pinasco MR. Study of the age-hardening in an $\mathrm{Au}-\mathrm{Cu}-\mathrm{Ag}$ dental alloy with $\mathrm{Pt}$ and $\mathrm{Pd}$ additions with dilatometry, hardness measurements and microstructural analysis. International Journal of Microstructure and Materials Properties. 2009; 4(4):487-506. http://dx.doi.org/10.1504/ IJMMP.2009.031401

2. Rivolta B, Gerosa R, Pinasco MR and Pellati G. Dilatometric analysis for investigating age hardening in a commercial precious metal dental alloy. Journal of ASTM International. 2009; 6(2):96-107.

3. Yasuda K. Age-hardening and related phase transformations in dental gold alloys. Gold bulletin. 1987; 20(4):90-103. http:// dx.doi.org/10.1007/BF03214661 the $\mathrm{Au}-\mathrm{Ag}-\mathrm{Cu}$ alloy, and the subsequent ordering, which is a powerful hardening mechanism, weakened its hardening effect by accelerating the softening mechanism.

\section{Conclusions}

The isothermal age-hardening behavior and related phase transformation, microstructural changes and elemental distribution of an $\mathrm{Au}-\mathrm{Ag}-\mathrm{Cu}$-based dental alloy were examined to clarify how the microstructural changes during and after phase transformation determine the age-hardenability of an Au-Ag-Cu-based dental alloy. The results are as follows.

- The rapid increase in hardness without an incubation period resulted from the rapid atomic diffusion by spinodal decomposition into the metastable Ag-rich' and Cu-rich' phases;

- The constant hardening after the apparent initial hardening was due to the subsequent transformation of the metastable Ag-rich' and Cu-rich' phases into the stable $\mathrm{Ag}$-rich $\alpha_{1}$ and $\mathrm{AuCu}$ I phases through the metastable $\mathrm{AuCu}$ I' phase;

- During the increase in hardness by the phase transformation, a fine block-like structure with high coherency formed in the grain interior, which transformed into a fine cross-hatched structure;

- The relatively coarse lamellar structure composed of $\mathrm{Ag}$-rich $\alpha_{1}$ and $\mathrm{AuCu} \mathrm{I}$ grew from the grain boundaries, initiating softening before the grain interior reached its maximum hardness; and

- The spinodal decomposition attributed to the rapid hardening by forming the fine block-like structure, and subsequent ordering into $\mathrm{AuCu} \mathrm{I}$, weakened its hardening effect by accelerating the lamellar-forming grain boundary reaction.

\section{Acknowledgements}

This research was supported by Basic Science Research Program through the National Research Foundation of Korea (NRF) funded by the Ministry of Education, Science and Technology (grant number: 2011-0010995)
4. Park MG, Yu CH, Seol HJ, Kwon YH and Kim HI. Age-hardening behaviour of a spinodally decomposed low-carat gold alloy. Journal of Materials Science. 2008; 43(5):1539-1545. http:// dx.doi.org/10.1007/s10853-007-2348-5

5. Udoh K, Fujiyama H, Hisatsune K, Hasaka M and Yasuda $\mathrm{K}$. Age-hardening associated with ordering and spinodal decomposition in a $\mathrm{AgCu}-40$ at\% Au pseudobinary alloy. Journal of Materials Science. 1992; 27(2):504-510. http:// dx.doi.org/10.1007/BF00543944

6. Hamasaki K, Hisatsune K, Udoh K, Tanaka Y, Iijima Y and Takagi O. Ageing behaviour in a dental low-gold alloy with high copper content. Journal of Materials Science: Materials in Medicine. 1998; 9(4):213-219. PMid:15348895. http://dx.doi. org/10.1023/A:1008888124024 
7. Hisatsune $\mathrm{K}$ and Udoh K. Age-hardening characteristics in an $\mathrm{AuCu}-1.4 \mathrm{at} . \% \mathrm{Ag}$ alloy. Journal of alloys and compounds. 1991; 176(2):269-283. http://dx.doi. org/10.1016/0925-8388(91)90035-T

8. Hisatsune K, Udoh K and Nakagawa M. Aging behaviour in a dental low carat gold alloy and its relation to CuAu II. Journal of the Less-Common Metals. 1990; 160:247-258. http://dx.doi. org/10.1016/0022-5088(90)90385-W

9. Nakagawa M and Yasuda K. Age-hardening and the associated phase transformation in an Au-55.2 at\% Cu-17.4 at\% Ag ternary alloy. Journal of Materials Science. 1988; 23(8):2975-2982. http://dx.doi.org/10.1007/BF00547478

10. Hernandez RI, Udoh K, Tanaka Y, Takuma Y, Winn H and Hisatsune $\mathrm{K}$. Phase transformation mechanisms in $(\mathrm{AuCu})_{1-\mathrm{X}} \mathrm{Pd}_{\mathrm{X}}$ pseudobinary alloys by direct aging method. Dental Materials Journal. 1999; 18(3):235-247. PMid:10786134. http://dx.doi. org/10.4012/dmj.18.235

11. Ohta M, Shiraishi T, Yamane M and Yasuda K. Age-hardening mechanism of equiatomic $\mathrm{AuCu}$ and $\mathrm{AuCu}-\mathrm{Ag}$ pseudo-binary alloys. Dental Materials Journal.1983; 2(1):10-17. PMid:6586339. http://dx.doi.org/10.4012/dmj.2.10

12. Yasuda $\mathrm{K}$ and Hisatsune $\mathrm{K}$. Microstructure and phase transformations in dental gold alloys. Gold bulletin. 1993; 26(2):50-66. http://dx.doi.org/10.1007/ BF03214725

13. Tanaka Y, Udoh K, Hisatsune K and Yasuda K. Early stage of ordering in stoichiometric AuCu alloy. Materials Transactions, JIM, 1998; 39(1):87-94.

14. Suryanarayana C and Norton MG. X-Ray diffraction: A practical approach. New York: Springer Science \& Business Media; 2003. p. 207-210.

15. Suh YC, Lee ZH and Ohta M. Precipitation behavior of Ag-Pd-In dental alloys. Journal of Materials Science: Materials in Medicine. 2000; 11:43-48. PMid:15348098. http://dx.doi. org/10.1023/A:1008937702722

16. Massalski TB. Binary alloy phase diagrams. 2nd ed. Materials Park: ASM International; 1990. p. 12-13 (Ag-Au), p. 28-29 (Ag-Cu), p. 358-362 (Au-Cu). 